\title{
Re: Robotic Management of Genitourinary Injuries From Obstetric and Gynecological Operations: A Multi-Institutional Report of Outcomes
}

\author{
Paul T. Gellhaus, Akshay Bhandari, M. Francesca Monn, Thomas A. Gardner, Prashanth \\ Kanagarajah, Christopher E. Reilly, Elton Llukani, Ziho Lee, Daniel D. Eun, Hani Rashid, \\ Jean V. Joseph, Ahmed E. Ghazi, GuanWu and Ronald S. Boris
}

Indiana University, Department of Urology, Indianapolis, IN, USA

BJU Int 2015;115:430-436.

\section{EDITORIAL COMMENT}

The incidence of urinary tract injury is low in most gynaecological operations. A systematic MEDLINE search for urinary tract injuries at gynaecologic surgery found that the ureteral injury rate was 7.8 per thousand cases for laparoscopic hysterectomy. However, undiagnosed urinary tract injury can cause significant postoperative morbidity for the patient and legal process for the gynaecologist. Open surgical management was traditionally the exact treatment approach for these conditions. This paper represents the largest cohort of robotic reconstructions of gynaecological injuries to date. The authors evaluated the use of robotic-assisted laparoscopy in the repair of obstetric or gynecologic surgery-associated genitourinary injuries in selected patients. It is a retrospective, multiinstitutional analysis of a relatively small group of patients with a heterogeneous group of urological injuries. They found that robotic-assisted laparoscopic repair of iatrogenic genitourinary injuries was technically feasible and was associated with acceptable short- to intermediate-term success.

The request for robotic-assisted reconstructive surgery and experienced robotic pelvic surgeons is likely to increase in the near future. While the role of robotic technology in genitourinary reconstruction remains in question, these data suggest that minimally invasive ureteral re-implant, ureteroureterostomy, and fistula repair may offer an acceptable alternative to open reconstruction.

\section{REFERENCES}

1. Rassweiler J1, Pini G, Gözen AS, Klein J, Teber D. Role of laparoscopy in reconstructive surgery. Curr Opin Urol 2010;20:471-482.

2. Gellhaus PT, Bhandari A, Monn MF, Gardner TA, Kanagarajah P, Reilly CE, Llukani E, Lee Z, Eun DD, Rashid H, Joseph JV, Ghazi AE, Wu G, Boris RS. Robotic management of genito-urinary injuries from obstetrical and gynecological operations: a multi-institutional report of outcomes. BJU Int 2015;115:430-436. 